\title{
Licenciatura em ciências biológicas e formação de professores para o ensino de física no ensino fundamental
}

Alexandre Leite dos Santos Silva alexandreleite@ufpi.edu.br 0000-0002-8239-9240 Universidade Federal do Piauí, Picos, Piauí, Brasil.

Suzana Gomes Lopes sqlopes@ufpi.edu.br 0000-0001-9071-9585 Universidade Federal do Piauí, Picos, Piauí, Brasil.

\begin{abstract}
RESUMO
A maioria dos professores de Ciências no Brasil são graduados em Ciências Biológicas e a literatura científica nacional aponta que para estes é um desafio ensinar conteúdos de Física no Ensino Fundamental. O desafio aumenta com a prescrição pela Base Nacional Comum Curricular do conteúdo de Física distribuído ao longo de todos os anos do Ensino Fundamental. Nesse contexto, este artigo tem como objetivo apresentar e problematizar os resultados de uma investigação sobre a formação docente para o ensino de Física no Ensino Fundamental em Cursos de Licenciatura em Ciências Biológicas. Para isso, foi feito o levantamento e a análise da carga horária e do conteúdo curricular de Física, através de arquivos on-line dos cursos de Licenciatura em Ciências Biológicas de doze universidades do estado de Minas Gerais. Constatou-se que tais cursos de formação inicial apresentam uma carga horária exígua para o componente curricular de Física, o qual tem abrangência limitada dos conteúdos específicos e é desenvolvido sem vinculação com a prática de ensino para o nível fundamental.
\end{abstract}

PALAVRAS-CHAVE: Professor de Ciências. Ensino de Física. Licenciatura em Ciências Biológicas. 


\section{INTRODUÇÃO}

Os professores de Ciências do Ensino Fundamental estão encarregados de ensinar os conteúdos de componentes curriculares de diversas áreas do conhecimento, de acordo com os Parâmetros Curriculares Nacionais (BRASIL, 1998). Essa característica do seu trabalho ficou mais evidente a partir da Base Nacional Comum Curricular (BNCC) que prescreveu para a disciplina Ciências nos últimos anos do Ensino Fundamental os conteúdos específicos aos campos da Biologia, da Física, da Química e das Geociências (BRASIL, 2017).

Entretanto, a exigência de que o professor de Ciências tenha um conhecimento amplo de diversas áreas choca-se muitas vezes com a sua formação, pois a maior parte dos professores de Ciências do Ensino Fundamental no Brasil são graduados na área de Biologia (BRASIL, 2009; MAGALHÃES JÚNIOR; PIETROCOLA, 2010; PAGANOTTI; DICKMAN, 2011; ROSA, 2015). Esse fato não pode ser um problema de acordo com as Diretrizes Curriculares Nacionais para os Cursos de Licenciatura em Ciências Biológicas:

\footnotetext{
A modalidade Licenciatura deverá contemplar, além dos conteúdos próprios das Ciências Biológicas, conteúdos nas áreas de Química, Física e da Saúde, para atender ao Ensino Fundamental e médio. A formação pedagógica, além de suas especificidades, deverá contemplar uma visão geral da educação e dos processos formativos dos educandos. Deverá também enfatizar a instrumentalização para o ensino de Ciências no nível fundamental e para o ensino de Biologia, no nível médio (BRASIL, 2001, p. 6).
}

Dessa forma, segundo essas diretrizes, os Cursos de Licenciatura em Ciências Biológicas devem prover formação científica e pedagógica para o ensino de Ciências no Ensino Fundamental, o que inclui o ensino de Física, que deve ser ministrado em todos os anos finais do Ensino Fundamental, conforme a BNCC (BRASIL, 2017). No entanto, segundo diversos pesquisadores, é comum os professores de Ciências graduados em Ciências Biológicas encontrarem dificuldades quanto ao ensino de Física no Ensino Fundamental (SILVA et al., 2002; MAGALHÃES JÚNIOR; PIETROCOLA, 2011).

Por isso, este trabalho se deteve ao objetivo de investigar, dentro do recorte do estado de Minas Gerais, o potencial formativo dos Cursos de Licenciatura em Ciências Biológicas para preparar os futuros professores de Ciências para o ensino de Física no Ensino Fundamental. Nessa direção, este texto foi organizado da seguinte forma: primeiro, explica como o componente curricular de Física é distribuído na BNCC; em seguida, mostra os resultados da revisão de literatura, com destaque para trabalhos acadêmicos recentes sobre as dificuldades dos professores de Ciências quanto ao ensino de Física no Ensino Fundamental. Na sequência, discute sobre os saberes que devem ser contemplados na formação profissional inicial dos professores. Após isso, apresenta a metodologia da pesquisa e os resultados e discussões, com os achados mais importantes. Consecutivamente, faz as considerações finais. 


\section{O ENSINO DE FÍSICA NOS ANOS FINAIS DO ENSINO FUNDAMENTAL NA BASE NACIONAL COMUM CURRICULAR}

A BNCC é possui caráter normativo e foi prevista na Constituição Federal de 1988, na Lei de Diretrizes e Bases da Educação Nacional, nas Diretrizes Curriculares Nacionais, e no Plano Nacional de Educação (BRASIL, 1988, 1996, 2013, 2014). Ela estabelece os componentes curriculares para as aprendizagens essenciais, expressas em conhecimentos, competências e habilidades, que devem obrigatoriamente constar nos currículos das redes públicas de ensino do país. A distribuição dos objetos de conhecimento, ou conteúdos disciplinares, relacionados com os componentes curriculares de Ciências para os anos finais do Ensino Fundamental, segundo a BNCC, deve se dar conforme o Quadro 1.

Quadro 1 - Unidades temáticas e objetos de conhecimento de Ciências para os anos finais do Ensino Fundamental, segundo a Base Nacional Comum Curricular

\begin{tabular}{|c|c|c|c|}
\hline Ano & Vida e Evolução & Matéria e Energia & Terra e Universo \\
\hline 60 & $\begin{array}{c}\text { - Célula como unidade } \\
\text { de vida } \\
\text { - Interação entre os } \\
\text { sistemas locomotor e } \\
\text { nervoso } \\
\text { - Lentes corretivas }\end{array}$ & $\begin{array}{l}\text { - Misturas homogêneas e } \\
\text { heterogêneas } \\
\text { - Separação de materiais } \\
\text { - Materiais sintéticos } \\
\text { - Transformações Químicas }\end{array}$ & $\begin{array}{l}\text { - Forma, estrutura e } \\
\text { movimentos da Terra }\end{array}$ \\
\hline 70 & $\begin{array}{c}\text { - Diversidade de } \\
\text { ecossistemas } \\
\text { - Fenômenos Naturais } \\
\text { e impactos ambientais } \\
\text { - Programas e } \\
\text { indicadores de saúde } \\
\text { pública }\end{array}$ & $\begin{array}{l}\text { - Máquinas simples } \\
\text { - Formas de propagação de } \\
\text { calor } \\
\text { - Equilíbrio termodinâmico } \\
\text { e vida na Terra } \\
\text { - História dos combustíveis } \\
\text { e das máquinas térmicas }\end{array}$ & $\begin{array}{l}\text { - Composição do ar } \\
\text { - Efeito estufa } \\
\text { - Camada de Ozônio } \\
\text { - Fenômenos Naturais } \\
\text { (vulcões, terremotos, } \\
\text { tsunamis) } \\
\text { - Placas tectônicas e } \\
\text { deriva continental }\end{array}$ \\
\hline 80 & $\begin{array}{l}\text { - Mecanismos } \\
\text { reprodutivos } \\
\text { - Sexualidade }\end{array}$ & $\begin{array}{l}\text { - Fontes e tipos de energia } \\
\text { - Transformação de energia } \\
\text { - Cálculo de consumo de } \\
\text { energia elétrica } \\
\text { - Circuitos elétricos } \\
\text { - Uso consciente de energia } \\
\text { elétrica }\end{array}$ & $\begin{array}{c}\text { - Sistema Sol, Terra e } \\
\text { Lua } \\
\text { - Clima }\end{array}$ \\
\hline 90 & $\begin{array}{l}\text { - Hereditariedade } \\
\text { - Ideias evolucionistas } \\
\text { - Preservação da } \\
\text { biodiversidade }\end{array}$ & $\begin{array}{l}\text { - Aspectos quantitativos das } \\
\text { transformações Químicas } \\
\text { - Estrutura da matéria } \\
\text { - Radiações e suas } \\
\text { aplicações na saúde }\end{array}$ & $\begin{array}{c}\text { • Composição, } \\
\text { estrutura e localização } \\
\text { do Sistema Solar no } \\
\text { Universo } \\
\text { - Astronomia e cultura } \\
\text { - Vida humana fora da } \\
\text { Terra } \\
\text { - Ordem de grandeza } \\
\text { astronômica } \\
\text { - Evolução estelar }\end{array}$ \\
\hline
\end{tabular}

Fonte: Brasil (2017).

O Quadro 1 mostra uma distribuição dos componentes curriculares de Biologia, Física, Química e Geociências ao longo de todos os anos finais do Ensino Fundamental. Isso modifica a programação convencional que desde a década de 1950 distribuía, nos níveis escolares correspondentes aos atuais anos finais do 
Ensino Fundamental nesse lapso temporal, os conteúdos de Geociências em parte do sexto ano; de Biologia em parte do sexto ano e no sétimo e oitavo anos; e de Física e de Química no nono ano (WORTMANN, 2001).

No entanto, com a BNCC, os conteúdos de Física passaram a ser distribuídos entre o sexto e o nono anos. Por exemplo, no sexto ano há o estudo das lentes corretivas, permitindo a introdução da óptica, que pode ser trabalhado interdisciplinarmente com os conteúdos de Biologia. No sétimo ano, são introduzidos conceitos da termodinâmica e sobre radiações, além da astronomia. No oitavo ano a eletricidade recebe destaque como conteúdo de Física. No nono ano, quanto à Física, há um enfoque na astronomia.

Dessa forma, a BNCC, como documento normativo, prescreve aos professores de Ciências a realização de um trabalho multidisciplinar (isto é, referente a um conjunto de disciplinas mesmo sem a exigência de uma conexão entre elas) e a necessidade de incluir o ensino de Física ao longo de todos os anos finais do Ensino Fundamental. Isso representa a nível de formação e trabalho docente um desafio.

\section{REVISÃO DE LITERATURA}

Através de uma pesquisa na literatura acadêmica nacional foram encontrados diversos trabalhos que relataram as dificuldades dos professores de Ciências quanto ao ensino de Física.

Marques et al. (2014), no âmbito de um curso de formação continuada realizado com professores das redes públicas de dois municípios do estado do Rio Grande do Sul, investigaram as dificuldades de professores de Ciências quanto ao ensino de Física nos anos finais do Ensino Fundamental. Eles constataram que mais de $80 \%$ dos professores participantes tinham alguma dificuldade para ensinar Física no Ensino Fundamental, como em compreender termos científicos, em contextualizar o conteúdo, em conhecer e aplicar metodologias adequadas. Ademais, descobriram que os professores se sentiam incapacitados e inseguros para o ensino de Física nos anos finais do Ensino Fundamental e que este ensino era desenvolvido de forma predominantemente livresca e tradicional, privilegiando o ensino de Biologia em detrimento da Física e da Química. Um dos motivos dessas dificuldades residia na falta de domínio do conteúdo a ser ensinado. Isso impossibilitava a adoção de estratégias de ensino adequadas.

Melo et al. (2015) estudaram as dificuldades encontradas pelos professores de Ciências de um município do estado do Pará quanto ao ensino de Física no Ensino Fundamental. Como resultado assinalaram as seguintes dificuldades: a falta de domínio e de contextualização do conteúdo; insegurança no ensino; dificuldade em realizar experimentos; abreviação do conteúdo de Física para a priorização do conteúdo de Biologia; e priorização dos conceitos da mecânica, em detrimento de conceitos importantes de outras áreas da Física. Na análise desses pesquisadores, uma das causas dessas dificuldades tinha relação com a formação profissional inicial desses professores, pois nenhum deles possuía formação específica em Física.

Medeiros e Loos (2017) fizeram um estudo sobre as exigências curriculares para o ensino de Física no Ensino Fundamental, comparando os Parâmetros Curriculares Nacionais (PCNs) e os livros didáticos. Constataram que é necessária uma adequação nos livros didáticos para atenderem de fato os PCNs. Ao 
confrontarem essas exigências curriculares para o ensino de Física com a formação dos professores de Ciências, após a análise de ementas de Cursos de Licenciatura em Ciências Biológicas com notas máximas no Exame Nacional de Desempenho de Estudantes (ENADE), concluíram que a formação oferecida se mostrava superficial ao considerarem o tempo destinado ao estudo desse componente curricular.

Silva e Santos (2017), no contexto de um curso de Física na modalidade de formação continuada com professores de Ciências de Uberlândia, estado de Minas Gerais, perceberam que eles tinham dificuldades relacionadas ao conhecimento da matéria a ser ensinada e insegurança no ensino, com limitações que iam desde o planejamento até a avaliação do processo de ensino-aprendizagem. Nesse caso, as dificuldades quanto ao ensino de Física diagnosticadas foram relacionadas à formação profissional inicial desses professores, graduados em cursos da área de Ciências Biológicas.

Cima et al. (2017) ao investigarem os fatores relacionados à redução do interesse dos alunos da Educação Básica quanto ao conteúdo de Física, observaram que há rejeição por parte dos próprios professores de Ciências do Ensino Fundamental.

Em resumo, as pesquisas supracitadas constataram que os professores de Ciências apresentavam em sua prática dificuldades quanto ao ensino de Física nos seguintes aspectos: planejamento do ensino, realização de experimentos, adoção de metodologias específicas, compreensão de conceitos, avaliação da aprendizagem, insegurança e desmotivação. Essa constatação é mais antiga e pode ser verificada também nos trabalhos de Cunha e Krasilchik (2000), Silva et al. (2002) e Sato e Magalhães Júnior (2006).

É necessário também esclarecer que nessas pesquisas as dificuldades quanto ao ensino de Física foram relacionadas à formação inicial dos professores, geralmente em cursos de Licenciatura em Ciências Biológicas. Tal fato contraria as expectativas do Conselho Nacional de Educação (BRASIL, 2001).

\section{A FORMAÇÃO PROFISSIONAL INICIAL E OS SABERES NECESSÁRIOS PARA A PRÁTICA DOCENTE}

As discussões sobre a formação profissional do professor remetem aos estudos sobre os saberes docentes, que remontam à década de 1970 (GAUTHIER et al., 2013). Esses estudos têm por fim subsidiar discussões sobre a profissionalização do professor e à construção da sua identidade, com base no pressuposto de que há um corpo básico de saberes que um professor necessita para a sua prática (SHULMAN, 2004; TAGLIATI; NARDI; CORTELA, 2018). A identificação desse corpo básico de saberes é imprescindível para o planejamento programas formativos para professores, especialmente para a formação profissional inicial, que tem um papel importante para a certificação e o reconhecimento profissional para o exercício da docência (GAUTHIER et al., 2013).

Nesse sentido, várias tipologias sobre os saberes docentes surgiram, como visto nos trabalhos de Shulman (2004), Tardif (2012) e Gauthier et al. (2013). No Brasil, em que os estudos sobre os saberes remontam à década de 1990, segundo Tagliati, Nardi e Cortela (2018), algumas tipologias também foram desenvolvidas (SAVIANI, 1996; CICILLINI, 2002; PIMENTA, 2009). Essas tipologias evidenciam que o exercício da prática docente depende da mobilização de diversos saberes 
(GAUTHIER et al., 2013). Além disso, a identificação desses saberes deve levar em conta o "contexto complexo e real no qual o ensino evolui" (GAUTHIER et al., 2013, p. 28).

Nessa direção, Saviani (1996) procurou categorizar os saberes docentes a partir do próprio processo educativo. Como resultado, ele elencou os seguintes tipos de saberes:

a) O saber atitudinal: refere-se a atitudes e posturas inerentes ao papel e à identidade profissional do educador;

b) O saber crítico-contextual: envolve a compreensão das condições sócio-históricas e do contexto em que desenvolve o trabalho educativo, de forma a ter condições de partir e voltar para a prática social no processo de ensino-aprendizagem;

c) O saber específico: trata-se do saber das disciplinas que integram os currículos escolares, que constituem um recorte do conhecimento socialmente construído e constituído como elemento educativo a ser assimilado;

d) O saber pedagógico: aquele proveniente das ciências da educação. Esse corpo de ideias identifica, justifica, orienta e explica a prática docente, por meio de teorias pedagógicas e psicopedagógicas sobre a educação, o ensino e a aprendizagem;

e) O saber didático-curricular: trata-se de um saber-fazer, que permeia as formas de organização e execução da prática educativa, integrando métodos e técnicas de ensino com outros elementos, como conteúdos e recursos, de forma dinâmica e objetiva.

Segundo Saviani (1996) esses são saberes que o professor deve dominar e que, portanto, devem integrar o seu processo formativo.

\section{METODOLOGIA}

Para a realização deste trabalho, foi feita a análise das grades curriculares, das fichas de disciplinas e dos projetos pedagógicos encontrados em registros em arquivos no ano de 2018, disponíveis na internet, em sites institucionais de cursos de Licenciatura em Ciências Biológicas de 12 instituições de ensino superior do estado de Minas Gerais. Optou-se por não mencionar as instituições, por motivos éticos, que foram designadas por números.

Os critérios de inclusão dos cursos na pesquisa foram: 1. cursos do estado de Minas Gerais, um recorte necessário para tonar a análise menos complexa; 2. cursos gratuitos; 3 . cursos presenciais; e 4. cursos em atividade. Tais parâmetros foram utilizados para a busca na página do sistema e-Mec no Portal do Ministério da Educação (BRASIL, 2019). Nas instituições com mais de um curso de Licenciatura em Ciências Biológicas cadastrado, foram elencados para a pesquisa apenas um dos cursos, preferencialmente os mais antigos e os que continham maior carga horária.

Nos arquivos analisados, determinou-se uma relação entre a carga horária analisou os objetivos e os conteúdos curriculares de Física propostos pelas 
ementas (fichas de disciplinas) e constantes nos Projetos Pedagógicos encontrados. Vale ressaltar que nesta análise foram consideradas somente as disciplinas da área de Física que eram obrigatórias para a conclusão do curso de Licenciatura em Ciências Biológicas.

\section{RESULTADOS E DISCUSSÃO}

Os principais resultados da pesquisa sinalizaram três aspectos que fragilizam o potencial formativo dos Cursos de Licenciatura em Ciências Biológicas analisados para o ensino de Física no Ensino Fundamental: i. a carga horária exígua; ii. a abrangência limitada dos conteúdos; e iii. a carência de direcionamento para a prática docente.

Os arquivos encontrados, quanto à inserção do componente curricular de Física, nos cursos de Licenciatura em Ciências Biológicas, permitiram a elaboração da Tabela 1, em que as instituições estão designadas por números:

Tabela 1 - A carga horária e os conteúdos de Física em cursos de Licenciatura em Ciências Biológicas analisados

\begin{tabular}{|c|c|c|c|}
\hline Instituição & $\begin{array}{l}\text { Porcentagem da carga } \\
\text { horária para o } \\
\text { conteúdo de Física } \\
\text { sobre a carga horária } \\
\text { total dos Cursos (\%) }\end{array}$ & $\begin{array}{l}\text { Disciplinas da área da } \\
\text { Física }\end{array}$ & $\begin{array}{l}\text { Conteúdo curricular } \\
\text { (por áreas) de } \\
\text { Física proposto } \\
\text { pelas ementas }\end{array}$ \\
\hline 1 & 1,87 & $\begin{array}{l}\text { Princípios físicos e } \\
\text { biofísicos }\end{array}$ & Não encontrado \\
\hline 2 & 2,15 & $\begin{array}{l}\text { Fundamentos da Física } \\
\text { Biofísica }\end{array}$ & $\begin{array}{c}\text { Radiação } \\
\text { Energia } \\
\text { Ondas } \\
\text { Eletricidade } \\
\text { Termodinâmica }\end{array}$ \\
\hline 3 & 2,30 & $\begin{array}{c}\text { Fundamentos de Física } \\
\text { Biofísica }\end{array}$ & $\begin{array}{l}\text { Mecânica } \\
\text { Termologia } \\
\text { Radiação } \\
\text { Eletricidade }\end{array}$ \\
\hline 4 & 3,81 & $\begin{array}{c}\text { Conceitos de Física Geral } \\
\text { Ensino de Biofísica }\end{array}$ & $\begin{array}{c}\text { Mecânica } \\
\text { Termodinâmica } \\
\text { Eletromagnetismo } \\
\text { Ondas } \\
\text { Radioatividades }\end{array}$ \\
\hline 5 & 1,82 & Física aplicada à Biologia & $\begin{array}{c}\text { Mecânica } \\
\text { Termodinâmica } \\
\text { Ondas } \\
\text { Óptica } \\
\text { Eletricidade } \\
\text { Radiação }\end{array}$ \\
\hline
\end{tabular}




\begin{tabular}{|c|c|c|c|}
\hline 6 & 3,27 & $\begin{array}{c}\text { Física para Ciências } \\
\text { Biológicas I } \\
\text { Física para Ciências } \\
\text { Biológicas II } \\
\text { Laboratório de Física } \\
\text { Geral }\end{array}$ & $\begin{array}{c}\text { Mecânica } \\
\text { Termodinâmica } \\
\text { Eletromagnetismo } \\
\text { Ondas } \\
\text { Óptica } \\
\text { Eletricidade } \\
\text { Magnetismo }\end{array}$ \\
\hline 7 & 3,70 & $\begin{array}{l}\text { Física I } \\
\text { Biofísica }\end{array}$ & $\begin{array}{l}\text { Mecânica } \\
\text { Eletricidade } \\
\text { Radiação }\end{array}$ \\
\hline 8 & 4,73 & $\begin{array}{c}\text { Física para Ciências } \\
\text { Biológicas } \\
\text { Biofísica }\end{array}$ & $\begin{array}{c}\text { Mecânica } \\
\text { Eletricidade } \\
\text { Magnetismo } \\
\text { Termodinâmica } \\
\text { Ondas } \\
\text { Óptica }\end{array}$ \\
\hline 9 & 3,36 & $\begin{array}{c}\text { Biofísica } \\
\text { Fundamentos de Física }\end{array}$ & $\begin{array}{l}\text { Mecânica } \\
\text { Onda } \\
\text { Óptica }\end{array}$ \\
\hline 10 & 1,72 & $\begin{array}{c}\text { Física aplicada a } \\
\text { Biociências }\end{array}$ & $\begin{array}{c}\text { Mecânica } \\
\text { Ondas } \\
\text { Eletromagnetismo } \\
\text { Termodinâmica } \\
\text { Óptica } \\
\text { Física moderna }\end{array}$ \\
\hline 11 & 1,73 & Biofísica & $\begin{array}{l}\text { Mecânica } \\
\text { Eletricidade }\end{array}$ \\
\hline 12 & 3,16 & $\begin{array}{l}\text { Física } \\
\text { Biofísica }\end{array}$ & Não encontrado \\
\hline
\end{tabular}

Fonte: Dados da pesquisa (2018).

Com base na Tabela 1, problematiza-se, com relação aos cursos de Licenciatura em Ciências Biológicas, quanto a se reservam uma parcela da carga horária para o ensino de Física correspondente às necessidades profissionais docentes para o ensino de Ciências no Ensino Fundamental. Essa carga horária deve ser direcionada tanto em conteúdo como em metodologia para o ensino de Física proporcionalmente ao que exigem as Diretrizes Curriculares Nacionais para os Cursos de Ciências Biológicas (BRASIL, 2001). No entanto, constatou-se que todas as universidades estudadas destinam menos que $5 \%$ da carga horária do curso de Licenciatura em Ciências Biológicas para disciplinas que abordam o conteúdo de Física, sendo que $1 / 3$ delas apresentam carga horária inferior a $2 \%$.

Conforme salientaram Cunha e Krasilchik (2000), as matrizes curriculares desses cursos são "biologizadas", o que faz sentido, por serem cursos de formação específica em Ciências Biológicas. Não é possível, dentro da carga horária destinada ao componente curricular de Física, que é tão exígua, trabalhar os objetos de conhecimento desta área prescritos pela BNCC para os anos finais do Ensino Fundamental e as suas respectivas metodologias de ensino, assim como concluíram Medeiros e Loos (2017).

Além da carga horária para o ensino de Física ser ínfima, nota-se que nem todo conteúdo escolar desse componente prescrito para o Ensino Fundamental está presente nas ementas das disciplinas analisadas. Para ilustrar, na instituição № 11 apenas os conteúdos de mecânica e eletricidade estão incluídos na programação 
curricular total, mas o professor de Ciências também necessita de domínio de saberes específicos, aqueles que integram os currículos escolares, da termodinâmica, da astronomia e de outras áreas da Física, que também estão prescritos pela BNCC (SAVIANI, 1996; BRASIL, 2017). Certamente, este é um fator limitante para o professor de Ciências em formação dominar o conteúdo. Conforme Gauthier et al. (2013, p. 30), "o tipo de conhecimento que o professor possui a respeito da matéria influi no seu ensino e na aprendizagem dos alunos". De acordo com outros estudos na área, a falta de domínio do conteúdo a ser ensinado influi na prática de ensino, na motivação do professor e na possibilidade de adoção de metodologias inovadoras (CARVALHO; GIL-PÉREZ, 2011; SHULMAN, 2004).

Verificou-se também, considerando os objetivos propostos nas ementas, que o conteúdo de Física, em muitos casos, não tem um direcionamento para a prática da docência na Educação Básica, atestado também pela escassez de disciplinas de metodologia do ensino de Ciências ou ausência das que se referem a como ensinar a Física. Para ilustrar, no curso da instituição № 4, a disciplina "Conceitos de Física Geral" tem como único objetivo "levar o estudante a adquirir a habilidade para compreender os processos físicos aplicados em sistemas biológicos", não havendo nenhuma menção ao ensino de Ciências no Ensino Fundamental. Nesse caso, o que tem que ser problematizado é o ensino de Física voltado apenas para a pesquisa pura na área da Biologia, deixando de lado o objetivo de subsidiar o ensino de Ciências. Por exemplo, a disciplina de "Biofísica" na instituição № 7 inclui na sua ementa os "métodos biofísicos de estudo (espectrofotometria, cromatografia, eletroforese)", não contemplando, além desse, nenhum conteúdo comumente trabalhado no Ensino Fundamental. Tais dados corroboram com Gatti e Nunes (2009), que afirmam que os conteúdos de Física nos cursos de Ciências Biológicas são ministrados sem articulação com o Ensino Fundamental, nem quando ministrado em forma de disciplina de Física ou nas disciplinas de metodologia.

A ausência de uma disciplina sobre metodologia de ensino de Física é até compreensível, quando se considera que o curso objetiva formar profissionais em Ciências Biológicas. Mas, ao mesmo tempo que se infere essa concepção, desconsidera-se um fator crucial para os egressos deste curso de graduação que é a área que este profissional irá atuar e que é listada em todos os projetospedagógicos analisados: professor de Ciências no Ensino Fundamental. Além disso, tal perfil é previsto inclusive pelas Diretrizes Curriculares Nacionais para os Cursos de Ciências Biológicas, que afirma que o curso deve oferecer disciplinas de Física e Química que possibilitem ao profissional formado atender à demanda tanto do Ensino Fundamental como do ensino médio (BRASIL, 2001). O conhecimento físico nos currículos analisados é de modo geral tratado apenas como recurso ou ferramenta para a pesquisa com foco na área de Ciências Biológicas. Por isso, os saberes didático-curriculares, que incluem os métodos e técnicas relacionados ao ensino de Física são obliterados, coibindo "a instrumentalização para o ensino de Ciências no nível fundamental" (SAVIANI, 1996; BRASIL, 2001, p. 6).

Os dados levantados apontam que a formação profissional inicial no âmbito dos cursos de Licenciatura em Ciências Biológicas em Minas Gerais analisados, dado ao seu caráter específico e disciplinar, ainda não é adequada para o ensino de Ciências nos anos finais do Ensino Fundamental, já que este trabalho exige um conhecimento multidisciplinar e generalista, segundo os PCNs (BRASIL, 1998) e a BNCC (BRASIL, 2017). Como esperar que um professor contextualize o seu ensino 
sem compreender os conceitos básicos e qual a metodologia mais adequada para ensiná-los? Por isso a formação inicial é tão importante, não apenas para proporcionar a habilitação e certificação de professores, mas também como um divisor de águas no que tange à aquisição de saberes necessários para a prática docente. Conforme Gauthier et al. (2013, p. 24), "se reconhece uma profissão principalmente pela posse de um saber específico formalizado e adquirido numa formação de tipo universitário". Nesse aspecto, os cursos de Licenciatura Plena em Ciências Naturais precisam ser mais valorizados, dado o seu caráter polivalente e voltado para a docência. Há estudos mostrando que os egressos desses cursos têm menos dificuldades quanto ao ensino de Física, provavelmente pelo seu formato, que abrange uma carga horária maior para o ensino de Física e de outros componentes curriculares, com o foco na docência a nível fundamental (MAGALHÃES JÚNIOR; PIETROCOLA; 2010, 2011).

Devido a essa fragilidade na formação inicial e à quantidade de professores de Ciências já em exercício, com formação em cursos de Licenciatura em Ciências Biológicas, é premente pensar em formação continuada, que se dá através de cursos e palestras oferecidos pelas secretarias da educação e por instituições de ensino superior (BASTOS; NARDI, 2008). Para isto, são necessários estudos que subsidiem a elaboração e implantação desses cursos, de forma a promover a construção de saberes relacionados à Física para o ensino de Ciências no Ensino Fundamental. Tais cursos devem abranger tanto saberes específicos de conteúdos de Física quanto os saberes didático-curriculares e pedagógicos vinculados a esse componente curricular.

\section{CONSIDERAÇÕES FINAIS}

A BNCC reforça o caráter multidisciplinar da disciplina Ciências, fazendo com que os conteúdos de Física permeiem todos os anos finais do Ensino Fundamental. Sendo assim, esse documento é um marco normativo que altera a distribuição convencional dos componentes curriculares da área de Ciências. Essa mudança se constitui em um desafio para a maioria dos professores de Ciências, que são graduados em Cursos de Licenciatura em Ciências Biológicas.

Por meio do estudo da produção acadêmica brasileira foram identificados diferentes entraves em relação ao ensino de Física no nível fundamental. Estas dificuldades estão relacionadas ao planejamento do ensino, ao uso de metodologias específicas, à inserção de experimentos, à avaliação da aprendizagem, à compreensão e ensino de conceitos físicos, e à desmotivação e insegurança no ensino.

O presente estudo mostrou a fragilidade no potencial formativo de cursos de Licenciatura em Ciências Biológicas de doze instituições mineiras para o ensino de Física nos anos finais do Ensino Fundamental. Essa fragilidade está presente na exígua carga horária reservada nos cursos para o componente curricular de Física, na limitação dos conteúdos específicos, e na ausência de um norteamento metodológico para o ensino de Física no Ensino Fundamental.

Por conseguinte, é problematizada a formação de professores de Ciências em cursos de Licenciatura em Ciências Biológicas para o ensino de Física no Ensino Fundamental, conforme estabelecido nas Diretrizes Curriculares Nacionais desses cursos. Enquanto a formação inicial oferecida nesses cursos é específica e 
disciplinar, o ensino de Ciências no Ensino Fundamental, de acordo com os PCNs e a BNCC, deve ter um caráter multidisciplinar e generalista.

Nesse sentido, são visualizadas duas possibilidades não excludentes de lidar com o problema apresentado: a criação de mais cursos de Licenciatura Plena em Ciências Naturais, dado o seu caráter polivalente; e o investimento em cursos de formação continuada para professores de Ciências em exercício, que contemplem saberes científicos e pedagógicos relacionados à Física.

Quanto aos cursos de Licenciatura Plena em Ciências Naturais, requer-se mais estudos que sinalizem o seu êxito para a formação multidisciplinar e um ensino mais equânime de Física, de Química, de Biologia e de Geociências no Ensino Fundamental, com vista na interdisciplinaridade, isto é, na busca de uma integração ou diálogo entre essas e outras disciplinas. Deve-se também problematizar se tal formação generalista não comprometeria a profundidade no tratamento dos conceitos científicos específicos nas aulas de Ciências e, por conseguinte, a qualidade do processo de ensino-aprendizagem. Nessa direção, pergunta-se qual seria o nível de conhecimento de Física, de Química, de Biologia e de Geociências que um professor de Ciências do Ensino Fundamental deveria possuir para não ser específico demais ou superficialmente generalista na sua prática de ensino.

A formação continuada é apontada como o caminho mais viável a curto prazo e diante do quadro atual de professores de Ciências graduados em Ciências Biológicas no país. No entanto, ainda há margens para pesquisas em cada contexto local e regional, para determinar quais as necessidades formativas específicas dos professores de Ciências em exercício quanto ao ensino de Física. 


\title{
GRADUATION COURSES IN BIOLOGICAL SCIENCES AND TEACHER TRAINING FOR PHYSICS TEACHING IN MIDDLE SCHOOLS
}

\begin{abstract}
Most Science teachers in Brazil have degrees in Biological Sciences. National scientific literature points out that for them it is a challenge Physics teaching in middle schools. The challenge increases with the prescription by the National Common Curricular Base of the content of Physics distributed throughout all years of middle school. In this context, this article aims to present and to problematize the results of an investigation about teacher training for Physics teaching in middle schools at Graduation Courses in Biological Sciences. For this, a survey and analysis of the workload and curricular content of Physics through online files from courses from twelve universities in Minas Gerais, Brazil It was found that such initial training courses have a small workload for the Physics curricular component, which has a limited scope of specific contents and is developed without being linked to teaching practice at the middle schools.
\end{abstract}

KEYWORDS: Science teacher. Physics teaching. Biological Sciences. 


\section{REFERÊNCIAS}

BASTOS, F.; NARDI, R. Debates recentes sobre a formação de professores: considerações sobre contribuições da pesquisa acadêmica. In: BASTOS, F.; NARDI, R. (Orgs.) Formação de professores e práticas pedagógicas no ensino de

Ciências: contribuições da pesquisa na área. São Paulo: Escrituras, 2008. p. 13-32.

BRASIL. Conselho Federal de Educação. Parecer № 81/85. Brasília, DF: 1985.

Constituição da República Federativa do Brasil de 1988. Brasília, DF:

Senado Federal, 1988. Disponível em:

<http://www.planalto.gov.br/ccivil 03/constituicao/constituicaocompilado.htm> . Acesso em: 23 jun. 2018.

. Lei de Diretrizes e Bases da Educação Nacional. Diário Oficial da União, Brasília, DF: 23 dez. 1996. Disponível em: $<$ http://www.planalto.gov.br/ccivil 03/Leis/19394.htm>. Acesso em: 23 jun. 2018.

. Ministério da Educação, Secretaria de Educação Fundamental.

Parâmetros Curriculares Nacionais: Ciências Naturais, ensino de quinta a oitava séries. Brasília, DF: 1998. 138 p. Disponível em:

$<$ http://portal.mec.gov.br/seb/arquivos/pdf/ciencias.pdf>. Acesso em: $19 \mathrm{fev}$. 2015.

Ministério da Educação, Secretaria de Educação Fundamental.

Parâmetros Curriculares Nacionais: Ciências Naturais, ensino de quinta a oitava séries. Brasília, DF: 1998. Disponível em:

$<$ http://portal.mec.gov.br/seb/arquivos/pdf/ciencias.pdf $>$. Acesso em: 23 mar. 2019.

Ministério da Educação, Conselho Nacional de Educação. Parecer CNE/CES 1.301/2001. Diretrizes Curriculares Nacionais para os Cursos de Ciências Biológicas. Diário Oficial da União, Brasília, DF: 07 dez. 2001. Seção 1, p. 25. Disponível em: <http://portal.mec.gov.br/cne/arquivos/pdf/CES1301.pdf>. Acesso em: 14 nov. 2014.

Instituto Nacional de Estudos e Pesquisas Educacionais Anísio Teixeira.

Estudo exploratório sobre o professor brasileiro com base nos resultados do Censo Escolar da Educação Básica 2007. Brasília, DF: Instituto Nacional de Estudos e Pesquisas Educacionais, 2009. Disponível em: < http://portal.mec.gov.br/dmdocuments/estudoprofessor.pdf >. Acesso em 23 mar. 2019. 
Diretrizes Curriculares Nacionais Gerais da Educação Básica. Brasília, DF: MEC, SEB, DICEI, 2013. 562 p. Disponível em:

$<$ http://portal.mec.gov.br/index.php?option=com docman\&view=download\&ali as=13448-diretrizes-curiculares-nacionais-2013-pdf\&ltemid=30192>. Acesso em: 23 jun. 2018.

Lei № 13.005, de 25 de junho de 2014. Aprova o Plano Nacional de Educação - PNE e dá outras providências. Diário Oficial da União, Brasília, DF: 26 jun. 2014. Disponível em: <http://www.planalto.gov.br/ccivil 03/ ato20112014/2014/lei/l13005.htm>. Acesso em: 23 jun. 2018.

Base Nacional Comum Curricular (BNCC). Educação é a Base. Brasília, DF: MEC/CONSED/UNDIME, 2017. 472 p. Disponível em: < http://basenacionalcomum.mec.gov.br/wpcontent/uploads/2018/12/BNCC 19dez2018 site.pdf>. Acesso em: 23 mar. 2019.

Sistema e-MEC, Instituições de Educação Superior e Cursos

Cadastrados, Brasília, DF: 2019. Disponível em: <http://emec.mec.gov.br/>. Acesso em: 07 abr. 2019.

CARVALHO, A. M. P.; GIL-PÉREZ, D. Formação de professores de Ciências: tendências e inovações. 10. ed. São Paulo: Cortez, 2011.

CHASSOT, I. A. Educação no ensino de Química. ljuí: UNIJUÍ, 1990.

CICILLINI, G. A. Conhecimento científico e conhecimento escolar: aproximações e distanciamentos. In ; NOGUEIRA, S. V. (Orgs.). Educação escolar: políticas, saberes e práticas pedagógicas. Uberlândia: EDUFU, 2002.

CIMA, R. C. et al. Redução do interesse pela Física na transição do ensino fundamental para o ensino médio: A perspectiva da supervisão escolar sobre o desempenho dos professores. Revista Electrónica de Enseñanza de las Ciencias, v. 16, n. 2, p. 385-409, 2017.

CUNHA, A. M. O.; KRASILCHIK, M. A formação continuada de professores de Ciências: percepções a partir de uma experiência. Reunião Anual da ANPED, 23, 2000, Caxambu. Anais [...] Caxambu, MG: ANPED, 2000. Disponível em: <http://23reuniao.anped.org.br/textos/0812t.PDF>. Acesso em: 29 mai. 2018. portuguesa, matemática e Ciências Biológicas. São Paulo: FCC/DPE, 2009. 158 p. (Coleção Textos FCC, 29) 
GAUTHIER, C. Por uma teoria da pedagogia: pesquisas contemporâneas sobre o saber docente. 3. ed. Tradução de Francisco Pereira. ljuí: Unijuí, 2013.

JÚNIOR, C. A. O. M.; OLIVEIRA, M. P. P. Análise de propostas para a formação de professores de Ciências do Ensino Fundamental. Alexandria: Revista de Educação em Ciência e Tecnologia, Florianópolis, v. 3, n. 2, p. 31-58, jul. 2010. Disponível em:

<https://periodicos.ufsc.br/index.php/alexandria/article/view/38098/29073>. Acesso em: 29 mai. 2018.

Atuação dos professores formados em Licenciatura Plena em Ciências.

Alexandria: Revista de Educação em Ciência e Tecnologia, Florianópolis, v. 4, n. 1, p. 175-198, maio 2011. Disponível em: <https://periodicos.ufsc.br/index.php/alexandria/article/view/37553/28840>. Acesso em: 19 fev. 2015.

MARQUES, N. L. R.; ARAÚJO, I. S.; VEIT, E. A. Formação e prática docente: uma pesquisa sobre dificuldades e atitudes de professores de Ciências do nível fundamental no ensino de Física. In: Encontro de Pesquisa em Ensino de Física, 15, 2014, Maresias. Anais [...] Maresias, SP: SBF, 2014. Disponível em: <http://www.sbf1.sbfisica.org.br/eventos/epef/xv/sys/resumos/T0090-1.pdf >. Acesso em: 10 abr. 2016.

MEDEIROS, E. A.; LOOS, M. R. O ensino de física na área de ciências naturais no ensino fundamental I e o ensino fundamental II segundo os Parâmetros Curriculares Nacionais. Revista do Professor de Física, Brasília, v. 1, n. 1, p. 1-11, 2017.

MELO, M. G. A.; CAMPOS, J. S.; ALMEIDA, W. S. Dificuldades enfrentadas por professores de Ciências para ensinar Física no Ensino Fundamental. Revista Brasileira de Ensino de Ciência e Tecnologia, Ponta Grossa, v. 8, n. 4, p. 241-251, 2015. Disponível em: <https://periodicos.utfpr.edu.br/rbect/article/view/2780>. Acesso em: 29 mai. 2018.

PAGANOTTI, A.; DICKMAN, A. G. Caracterizando o professor de Ciências: quem ensina tópicos de Física no Ensino Fundamental? Encontro Nacional de Pesquisa em Educação em Ciências, 8, 2011, Campinas. Atas[...] Campinas, SP: ABRAPEC, 2011. Disponível em:

<http://www.nutes.ufrj.br/abrapec/viiienpec/resumos/R0793-2.pdf>. Acesso em: 23 mar. 2019.

PIMENTA, S. G. Formação de professores: identidade e saberes da docência. In 2009. 
ROSA, L. S. Os desafios da formação de professores de Ciências para o Ensino Fundamental. 2015. Dissertação (Mestrado) - Programa de Pós-Graduação em Educação em Ciências da Universidade Federal de Rio Grande, Rio Grande, Rio Grande do Sul, 2015.

SATO, L.; JÚNIOR, C. A. O. M. Investigação das dificuldades dos professores de Ciências com relação à prática de ensino por meio da experimentação. EDUCERE: Revista da Educação, Umuarama, v. 6, n. 1, p. 35-47, jan.-jun. 2006. Disponível em:

<http://www.revistas.unipar.br/index.php/educere/article/viewFile/157/131>. Acesso em: 21 abr. 2019.

SAVIANI, D. Os saberes implicados na formação do educador. In: BICUDO, M. A. V.; JÚNIOR, C. A. S. (Orgs.) Formação do educador: dever do estado, tarefa da universidade. São Paulo: Editora Unesp, 1996. p. 145-155. (Coleção Seminários e Debates, 2).

SHULMAN, L. The wisdom of practice: essays on teaching, learning, and learning to teach. San Francisco: Wiley Imprint., 2004.

SILVA, R. C. et al. Um higrômetro de vagem e a Física no Ensino Fundamental. Caderno Brasileiro de Ensino de Física, Florianópolis, v. 19, n. 2, p. 242-252, ago. 2002. Disponível em:

<https://periodicos.ufsc.br/index.php/fisica/article/view/6624/6122>. Acesso em: 29 mai. 2018.

SILVA, A. L. S.; SANTOS, S. M. Um curso de Física para professores de Ciências Naturais do Ensino Fundamental. Cadernos da Pedagogia, São Carlos, v. 10, n. 20, p. 43-50, jan.-jun. 2017. Disponível em:

<http://www.cadernosdapedagogia.ufscar.br/index.php/cp/article/view/992/343 >. Acesso em: 29 mai. 2018.

TAGLIATI, J. R.; NARDI, R.; CORTELA, B. S. C. Um estudo sobre os potenciais formativos de cursos de licenciatura em Física do Estado de Minas Gerais. Revista Brasileira de Ensino de Ciência e Tecnologia, Ponta Grossa, v. 11, n. 2, p. 384402, 2018. Disponível em: <https://periodicos.utfpr.edu.br/rbect/article/view/8472>. Acesso em: 21 abr. 2019.

TARDIF, M. Saberes docentes e formação profissional. 14ạ Ed. Petrópolis: Vozes, 2012. 
WORTMANN, M. L. C. Currículo e Ciências: as especificidades pedagógicas do ensino de Ciências. In: COSTA, M. V. (Org.). O currículo nos limiares do

contemporâneo. 3. ed. Rio de Janeiro: DP\&A, 2001. p. 129-158.

Recebido: 21 abr. 2019

Aprovado: 06 mai. 2020

DOI: 10.3895/rbect.v13n3.10008

Como citar: SILVA, A. L. S; LOPES, S. G. Licenciatura em ciências biológicas e formação de professores para o ensino de física no ensino fundamental. Revista Brasileira de Ensino de Ciência e Tecnologia, Ponta Grossa, v.13, n. 3, p. 109-125, set./dez. 2020. Disponível em:

$<$ https://periodicos.utfpr.edu.br/rbect/article/view/10008>. Acesso em: XXX

Correspondência: Alexandre Leite dos Santos Silva - alexandreleite@ufpi.edu.br

Direito autoral: Este artigo está licenciado sob os termos da Licença Creative Commons-Atribuição 4.0 Internacional. 